\title{
Anomalous Origin and Course of Coronary Artery-Presentation of Three Cases
}

\author{
Ankit Maheshwari' ${ }^{1}$, Soumyadip Saha', Tanunita Mondal' ${ }^{2}$, Harpreet Singh Minhas ${ }^{1}$, \\ Muhammad Abid Geelani ${ }^{1}$ \\ ${ }^{1}$ Department of CTVS, Govind Ballabh Pant Institute of Postgraduate Medical Education \& Research, Delhi, India \\ ${ }^{2}$ Department of Anaesthesia, Govind Ballabh Pant Institute of Postgraduate Medical Education \& Research, Delhi, India \\ Email: docankitm05@gmail.com
}

How to cite this paper: Maheshwari, A., Saha, S., Mondal, T., Minhas, H.S. and Geelani, M.A. (2019) Anomalous Origin and Course of Coronary Artery-Presentation of Three Cases. World Journal of Cardiovascular Surgery, 9, 89-95.

https://doi.org/10.4236/wjcs.2019.98011

Received: May 20, 2019

Accepted: August 24, 2019

Published: August 27, 2019

Copyright (c) 2019 by author(s) and Scientific Research Publishing Inc. This work is licensed under the Creative Commons Attribution International License (CC BY 4.0).

http://creativecommons.org/licenses/by/4.0/

\begin{abstract}
Anomalous origin of coronary arteries may be encountered coincidentally in the presence of unrelated pathology or when these are affected directly. This may directly be responsible for affecting the procedure or outcome. Various types of anomalies of origin, as well as course of coronary arteries, have been classified in the past. Here we report 3 cases of anomalous origin of coronary arteries in different scenarios. First case had anomalous coronary with bicuspid aortic valve with dilated ascending aorta for which Bentall's procedure was done, while the second and third cases were anomalous coronaries with coronary artery disease for which coronary artery bypass grafting was done.
\end{abstract}

\section{Keywords}

Anomalous Origin of Coronary Artery, Bentall's Procedure, Coronary Artery Bypass Graft

\section{Introduction}

Coronary artery anomalies are congenital abnormalities that have been described in the past and discussed extensively by Angelini [1]. Presentation of these anomalies is variable, and these can be challenging intraoperatively various cardiac conditions. We faced 3 such cases which we present in this article.

\section{Case 1}

A 50 years old male presented with dyspnoea on exertion NYHA grade II, angina on exertion class II for the last one and half years and palpitation for the last six months. There was a history of smoking for 20 years and alcoholism for 10 years. Clinical evaluation suggested aortic stenosis. Routine preoperative workup 
showed normal blood Investigations. X-ray showed dilated ascending aorta. Echocardiography showed bicuspid and calcified aortic valve with an annulus of $3.2 \mathrm{~cm}$ and dilated ascending aorta of $4.5 \mathrm{~cm}$ suggestive of severe aortic stenosis with the normal functioning mitral valve. Computed tomographic coronary angiography (CT Coronary) (Figure 1) revealed increased diameter of ascending aorta of $4.5 \mathrm{~cm}$, separate opening of Left anterior descending artery (LAD) and Left circumflex (LCx) artery from left coronary sinus with normal course, along with absent Left main coronary artery.

Patient was taken up for surgery after informed consent. Bentall's procedure was planned as the ascending aorta was dilated and aortic valve was calcified.

Intraoperatively, the ascending aorta was found to be thinned out and dilated. The arch vessels were normal. After aorto-bicaval cannulation and initiating cardiopulmonary bypass, the temperature was lowered to $32^{\circ} \mathrm{C}$. Antegrade root cardioplegia was given and aorta was cross clamped. Aorta was incised near root and both coronary ostia were examined. It was found that the LAD \& LCx were arising separately from left coronary sinus and Right coronary artery (RCA) was arising from right sinus. Calcified aortic valve was excised. LCx and LAD ostia were harvested as a single button and RCA ostia as a separate button (Figure 2). Dilatation of ascending aorta ended proximal to the origin of Innominate artery. The ascending aorta was divided proximal to the innominate artery. Aortic valve conduit 25 SJM (Master Series Aortic Valve graft SJM) was anastomosed proximally to the aortic root and distally to the ascending aorta. The coronary ostia were implanted at the conduit. Rewarming and deairing was done. Left ventricular vent was removed. The patient was gradually weaned off CPB. A pacing wire and mediastinal drain were inserted. The median sternotomy was closed. Post-operative period was uneventful. Post-operative Echocardiography demonstrated normally functioning prosthetic aortic valve.

Patient was discharged with Tab Warfarin and Tab Aspirin for anticoagulation.

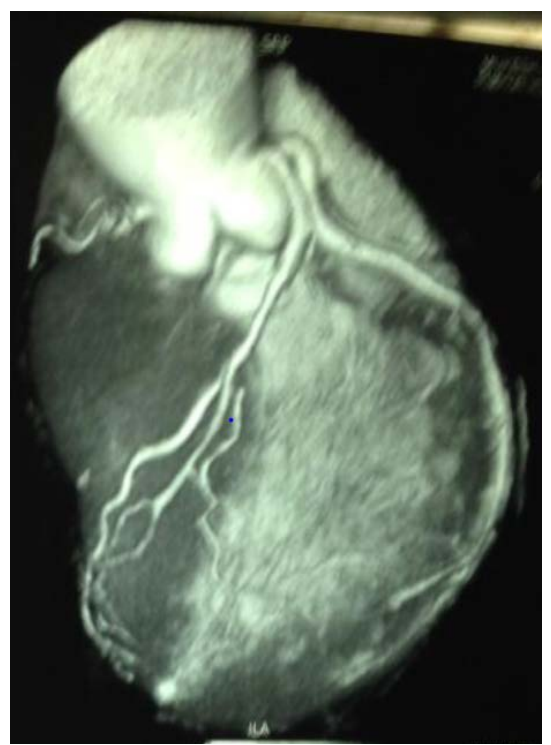

Figure 1. CT coronary angiography image showing separate origin of LAD and LCX. 


\section{Case 2}

A 60-Year-old male presented with chest pain for which evaluation was done. ECG suggested of ischaemic changes for which angiography was done. The patient was non-diabetic and non-hypertensive. Angiography (Figure 3) suggested the narrowing of left main coronary artery and the origin of both left main coronary artery and right coronary artery from the right sinus, left main coronary artery from right sinus above right coronary artery posteriorly. There was left anterior descending artery (LAD) narrowing 90 percent and ramus narrowing 80 percent. Echocardiography suggested normal ejection fraction of $60 \%$. Laboratory investigations were normal and pre-anesthetic fitness was obtained. Decision to perform coronary artery bypass grafting was taken. Intraoperatively, vessels were found to be atheromatous. The patient was operated and left internal mammary artery was anastomosed to LAD, and reverse saphenous vein grafts from aorta to ramus and diagonal. Distal runoff was good. Post operatively, the patient recovered well, and sternal incision site remained healthy. Patient was discharged on the $10^{\text {th }}$ post-operative day.

\section{Case 3}

A 55-year-old female presented with acute onset chest pain with hypotension. ECG changes suggested ischaemic changes followed by which resuscitation and stabilisation was done. On coronary angiography, coronary anomaly was seen and there were separate origin of left anterior descending artery (LAD) and left circumflex artery LCX from left coronary sinus (Figure 4), with absent left main coronary artery and normal right coronary artery. Laboratory investigations were found to be normal and echocardiography revealed ejection fraction was $60 \%$ with no regional wall motion abnormality. After preoperative workup and

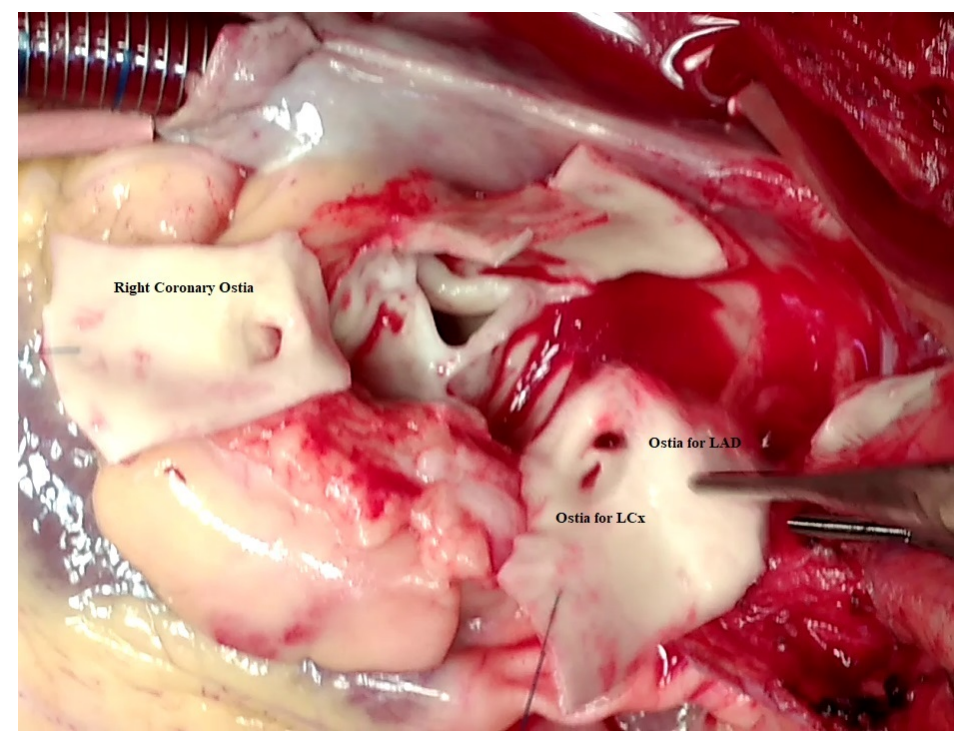

Figure 2. Intra-operative image showing right coronary button harvested and separate origin of LAD and LCX. Here, LAD and LCX are harvested as a single coronary button. 


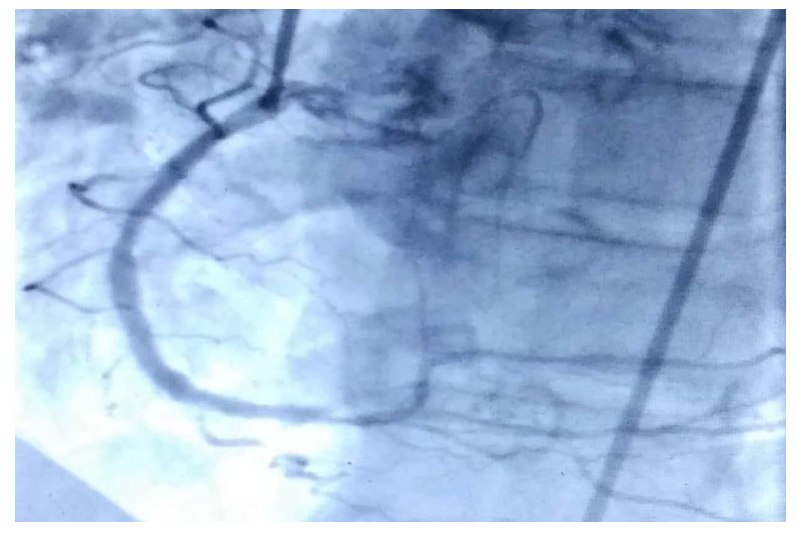

Figure 3. Coronary angiography image showing origin of right coronary artery and left main coronary artery from right sinus.

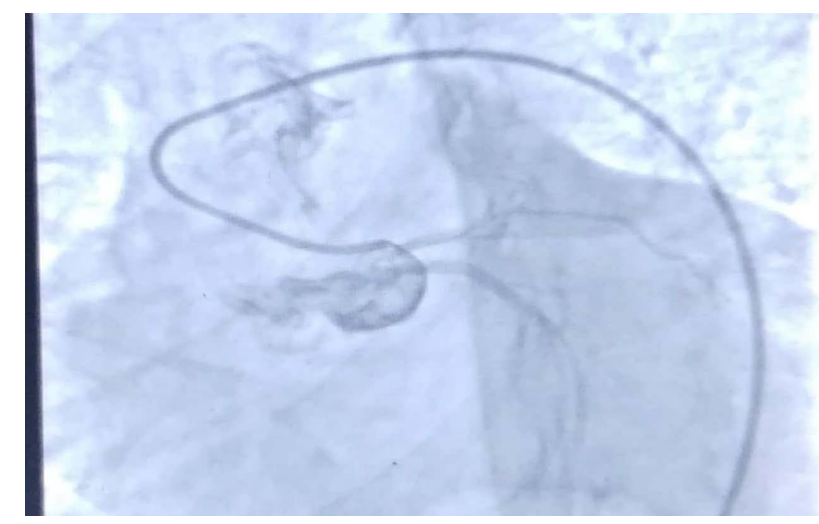

Figure 4. Coronary angiography showing separate origin of LAD and LCX from left coronary sinus.

obtaining pre-anaesthetic fitness, coronary artery bypass grafting was done. Left internal mammary artery to LAD grafting was done. Reverse saphenous vein graft was anastomosed to aorta proximally, and diagonal and OM distally. Vessels were atheromatous and distal runoff was good. Post operatively, the patient recovered well. Incision site remained healthy and the patient was discharged on $11^{\text {th }}$ post-operative day.

\section{Discussion}

During the developmental period, coronary buds arise from the sinuses of Valsalva and their location depends on the region of the division of the bulbous cordis into aorta and pulmonary arteries. These buds fuse with the vascular network in the heart later. Any variation in this process leads to coronary artery anomalies. The points of origin of the coronary buds are located so that, with the subsequent division of this portion, they will be situated on the right and left sinuses of Valsalva (RSV and LSV) [2].

Angelini and co-workers suggested "normal" as more than $1 \%$ of frequency and anomaly as less than $1 \%$ of the general population. Symptomatic patients with anomalous coronary can be treated medically, by intervention or by sur- 
gery, especially for those having associated anomalies or for preventing sudden death [1]. Patients may present with variable presentations like Ischemia or coincidental valvular heart disease. $26 \%$ of coronary anomalies may have aortic root abnormality, classic example being bicuspid aortic valve. Bicuspid aortic valve is associated with a higher incidence of coronary anomalies [3]. Absent left main coronary artery, and the left anterior Descending and left circumflex coronary arteries originating directly from the aorta is seen rarely ( $1 \%$ of general population) [4].

There have been incidents of sudden cardiac death due to unknown reasons. Hence, some guidelines ask people with coronary anomalies to refrain from competitive sports or strenuous activities [5]. Currently various modalities to diagnose them preoperatively are conventional coronary angiography, CT coronary angiography or MRI. Contrary to the thinking and according to prevailing opinion, coronary segments with an anomalous course are no more vulnerable to obstructive disease than are normal segments in the same individual [6]. Recent American College of Cardiology/American Heart Association Task Force recommends, "surgical procedures are the only therapies available for correcting these anomalies" [7] [8].

In all the 3 cases, pre-operative planning was very important. The patient's coronary anatomy is important for giving direct cardioplegia and harvesting coronary buttons in the first case. Even though it was convenient in this case, coronary button mobilisation can be difficult before implantation and care should be taken to ensure proper implantation into the conduit avoiding excessive tension. The outcome of the procedure depended on this step of coronary button harvesting, which was managed successfully. Proper deairing ensures avoiding air entering these coronary arteries and thereby preventing ventricular dysfunction in the post-operative period.

Whenever diagnosed preoperatively in cases of coronary artery disease, basic principles of CABG must be followed. Sometimes, the aortic origin of the artery may require modifications if it is associated with another surgery or if it affects future outcome in preventing ischaemia. The modifications may include unroofing or reimplantation [9]. In our $2^{\text {nd }}$ and $3^{\text {rd }}$ case, preoperative workup included detailed echocardiography as anomalous coronaries may be associated with valvular lesions, and to assess for regional wall motion abnormalities. Intraoperatively, it was important to define the level of obstruction and correlate it with the angiographic findings. Distal runoff was good in both cases. Anastomotic technique and proper lie of the graft to ensure adequate flow and to prevent kinking of the graft is important. Good revascularisation was achieved in both cases as the patient recovered well in the post-operative period.

Brothers et al. observed that one-third of their postoperative patients had residual "ischaemic" abnormalities detected using a combination of exercise stress testing, stress echocardiography and myocardial perfusion studies [10]. Long term accumulated data is required for making further recommendations [11]. 


\section{Conclusion}

As we realized from the above three cases, anomalous coronary arteries may sometime pose a challenge during the intraoperative course especially when coronary buttons need to be harvested. Preoperative workup and intraoperative judgement are crucial for better outcomes.

\section{Consent}

Informed consent was obtained from all patients whose cases are described.

\section{Conflicts of Interest}

The authors declare no conflicts of interest regarding the publication of this paper.

\section{References}

[1] Angelini, P. (2007) Coronary Artery Anomalies an Entity in Search of an Identity. Circulation, 115, 1296-1305. https://doi.org/10.1161/CIRCULATIONAHA.106.618082

[2] Villa, A.D.M., Sammut, E., Nair, A., Rajani, R., Bonamini, R. and Chiribiri, A. (2016) Coronary Artery Anomalies Overview: The Normal and the Abnormal. World Journal of Radiology, 8, 537-555. https://doi.org/10.4329/wjr.v8.i6.537

[3] Sans-Coma, V., Duran, A.C., Fernandez, B., Fernandez, M.C., Lopez, D. and Arque, J.M. (1999) Coronary Artery Anomalies and Bicuspid Aortic Valve. In: Angelini, P., Ed., Coronary Artery Anomalies. A Comprehensive Approach, Lippincott Williams \& Wilkins, Philadelphia, PA, 17-25.

[4] Kouchoukos, N., Blackstone, E., Hanley, F. and Kirklin, J. (2012) Kirklin/BarretBoyes Cardiac Surgery. 4th Edition, Saunders, Philadelphia, PA, 22.

[5] Maron, B.J. and Zipes, D.P. (2005) Introduction: Eligibility Recommendations for Competitive Athletes with Cardiovascular Abnormalities-General Considerations. Journal of the American College of Cardiology, 45, 1318-1321. https://doi.org/10.1016/j.jacc.2005.02.006

[6] Angelini, P. (2002) Coronary Anomalies Incidence, Pathophysiology, and Clinical Relevance. Circulation, 105, 2449-2454. https://doi.org/10.1161/01.CIR.0000016175.49835.57

[7] Cheezum, M.K., et al. (2017) Anomalous Aortic Origin of a Coronary Artery From the Inappropriate Sinus of Valsalva. Journal of the American College of Cardiology, 69, 1592-608. https://doi.org/10.1016/j.jacc.2017.01.031

[8] Van Hare, G.F., Ackerman, M.J., Evangelista, J.A., et al. (2015) Eligibility and Disqualification Recommendations for Competitive Athletes with Cardiovascular Abnormalities: Task Force 4: Congenital Heart Disease: A Scientific Statement from the American Heart Association and American College of Cardiology. Circulation, 132, e281-e291.

[9] Ong, C.S., Cameron, D.E. and Jacobs, M.L. (2018) Surgical Management of Anomalous Coronary Arteries. Annals of Cardiothoracic Surgery, 7, 604-610. https://doi.org/10.21037/acs.2018.08.02

[10] Brothers, J.A., et al. (2009) Exercise Performance and Quality of Life Following Surgical Repair of Anomalous Aortic Origin of a Coronary Artery in the Pediatric Pop- 
ulation. The Journal of Thoracic and Cardiovascular Surgery, 137, 380-384. https://doi.org/10.1016/j.jtcvs.2008.08.008

[11] Liberthson, R.R. (2015) Management Implications for Anomalous Aortic Origin of Coronary Arteries. JACC: Cardiovascular Imaging, 8, 1250-1251. 